\title{
FUNDAMENTAL STUDIES OF PASSIVITY AND PASSIVITY BREAKDOWN
}

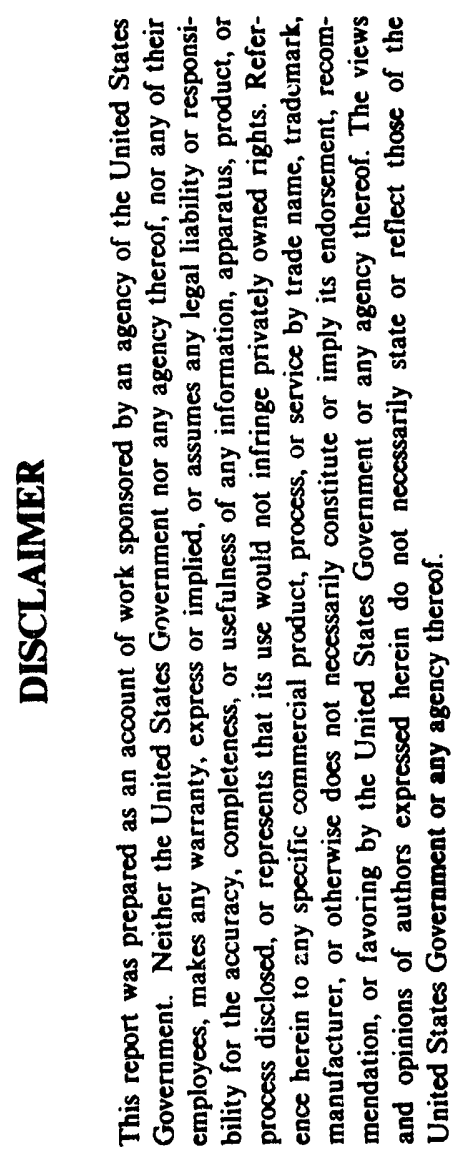

Approved by:

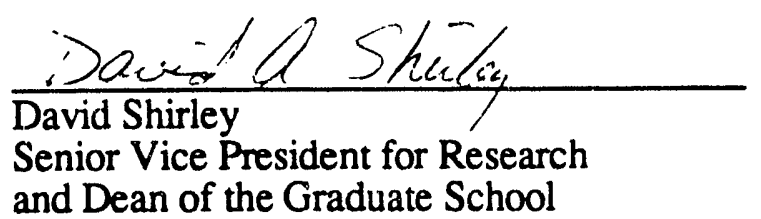

Senior Vice President for Research

and Dean of the Graduate School

\author{
Proposal for Research
}

Prepared by:

Digby D. Macdonald

Professor of Materials Science and Engineering and Director of the Center for Advanced Materials

The Pennsylvania State University

517 Deike Building

University Park, PA 16802

Prepared for:

U. S. Department of Energy

Division of Acquisition Management

ER-64, G236, GTN

Washington, DC 20585

\section{Continuation of Grant No. DE-FG02-91ER45461}

(J. Darby, Office of Basic Energy Sciences)

April 20, 1992
Submitted by:

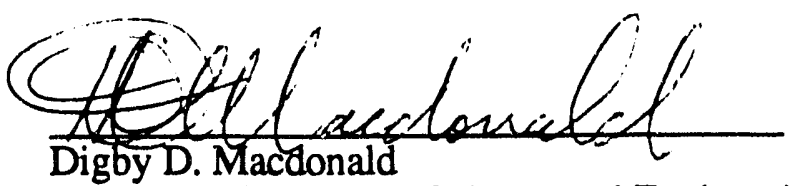

Professor of Materials Science and Engineering and Director of the Center for Advanced Materials 
The Pennsylvania State University proposes a second year of the current isree year Grant No. DE-FGO2-91ER45461, to continue our studies of the effects of minor alloying elements on passivity breakdown and of photo effects on the properties of passive films, and to use electrochemical and photoelectrochemical techniques to explore the transport and kinetic properties of vacancies and charge carriers in the films and at the metal/film and film/solution interfaces. In particular, we will continue to develop the point defect and solute/vacancy interaction models to account for the distributions in the critical voltage and induction time for passivity breakdown by incorporating the thermodynamics of absorption of halide ions into surface oxygen vacancies, by invoking different mechanisms for cation vacancy generation at the film/solution interface, by extending the models to passive films on metal substrates having variable cation oxidation states, and by deriving rate laws for the growth of passive films in response to an imposed voltage perturbation.

We will continue to use electrochemical impedance spectroscopy to determine the transport properties of vacancies in passive films and to explore the kinetics of vacancy generation and annihilation at the metal/film and film/solution interfaces. Principal emphasis is being placed on the development of nonlinear regression techniques for extracting kinetic and transport properties for passive films frorn experimental impedance data. We are also exploring the use of photoelectrochemical impedance spectroscopy (PEIS), developed during our past reporting period, to explore photoelectrochemical processes that occur in passive films under illumination and to characterize coupling between electronic and crystallographic defects in the films. During the past year, we have completed an extensive phtoelectrochemical study of tungsten, which has demonstrated the ability of PEIS to characterize defect coupling. A paper on this work is currently being prepared.

We have also begun to explore the kinetics of localized attack by modifying the coupled environment fracture model we recently developed for describing stess corrosion cracking to describe the rate of pit penetration of a metal or alloy substrate. During this past year we have used this model in conjunction with our passivity breakdown distribution models to 
derive damage functions (distributions in pit depth versus time) for pitting attack. To our knowledge, this is the first deterministic calculation of damage functions for localized corrosion and we regard the development of damage function analysis (DFA) to be a major advance in corrosion science and engineering. We are now using DFA to predict damage due to pitting corrosion in condensing heat exchangers under a separate contract with the Gas Research Institute and we are now applying the same techniques to predict damage due to stress corrosion cracking in $w$ ater cooled nuclear reactor heat transport circuits in the present program. In addition to the application of DFA to industrially-important systems, we are continuing our theoretical work on the effects of alloying on the development of damage with the ultimate goal of devising purely deterministic methods for predicting corrosion damage.

The current program supports three graduate students and one post-doctoral fellow in two departments: Materials Science and Engineerirag (College of Earth and Mineral Sciences) and Engineering Science and Mechanics (Colis ge of Engineering). Finally, the work carried out in this program has resulted in the award of two major scientific prizes to the PI during the past reporting period: The Carl Wagner Award from The Electrochemical Society (October, 1991) and the Willis Rodney Whitney Award from The National Association of Corrosion Engineers (April, 1992). 


\section{INTRODUCTION AND PAST ACHIEVEMENTS}

We propose to continue our fundamental research on passivity and passivity breakdown, starting on or about September 1, 1992, as the second year of Grant No. DE-FG0291ER45461, "Fundamental Studies of Passivity and Passivity Breakdown." This current grant follows one that was held by the Principal Investigator (Dr. D. D. Macdonald) while at SRI International in Menlo Park, California. However, on July 1, 1991, Dr. Macdonald joined The Pennsylvania State University as Professor of Materials Science and Enginering and as Director of the Center for Advanced Materials. While the current grant seeks to continue the original under the prior Grant No. DE-FG03-84ER45164, certain aspects of the work have been greatly expanded in light of our findings over the past year.

During the past four years in this program (including the three year incrementally-funded grant prior to the present grant), we developed and experimentally tested various physical models for the growth and breakdown of passive films on metal surfaces. These models belong to a general class termed "point defect models" (PDMs), in which the growth and breakdown of passive films are described in terms of the movement of anion and cation vacancies. Specifically, our work during the past four years of this program resulted in:

(1) Derivation of a theory for the steady-state properties of passive films on metal surfaces. ${ }^{1}$ This theory was found to give an accurate description of the dependence of the steady-state film thickness and current on potential and $\mathrm{pH}$ for passive nickel in phosphate solutions, as derived in this work, and for a variety of metals and alloys in various aqueous media as determined from data from the literature.

(2) Demonstrated that the passive film on nickel is a cation conductor whiereas that on tungsten is an oxygen ion conductor. Ionic conduction in the passive film on nickel involves the irreversible ejection of cations from the film into the solution at the film/solution interface.

(3) Development of deterministic models for the distributions in the critical voltage and induction time for passivity breakdown. ${ }^{2-5}$ The distributions in these parameters are attributed to distributions in the breakdown sites in terms of the cation vacancy diffusivity.

(4) Derivation of distribution functions for the critical yoltage $\left(V_{c}\right)$ and induction time ( $\left.\mathrm{t}_{\mathrm{ind}}\right)$ for passivity breakdown using different distributions for the breakdown sites with respect to the cation 
vacancy diffusivity. The continuous distributions used include the log and normal distributions. Other distributions (student " $t$ " and $\chi$ square) are now being developed. Numerical analysis of the derived distributions in $\mathrm{V}_{\mathrm{c}}$ and $\mathrm{t}_{\text {ind }}$ is now being performed for comparison with experimental data.

(5) Development of a coupled environment model for pit growth. We are currently coupling this model with the distribution functions for $\mathrm{V}_{c}$ and $t_{\text {ind }}$ to derive a deterministic treatment for predicting damage functions for pitting corrosion (distribution in pit depth versus exposure time).

(6) Development of the solute-vacancy interaction model to account for the effects of alloying elements on the critical voltage and induction time for pit nucleation on an alloy surface. 4,5

(7) Unification of the point defect and solute/vacancy interaction models to explore the effects of alloying elements on the distributions in the critical voltage $\left(V_{c}\right)$ and induction time $\left(t_{i n d}\right)$ for passivity breakdown. The model was then used to account for critical pitting potential data for $\mathrm{Fe}-\mathrm{Cr}$-Ni-Mo alloys taken from the literature.

(8) Measurement of distributions in the critical breakdown voltage and induction time for pit nucleation on $\mathrm{Ni}-\mathrm{xAl}, \mathrm{Ni}-\mathrm{xTi}$, and $\mathrm{Ni}-\mathrm{xMo}$ alloys in buffered boric acid and buffered chloride solutions. These data agree with the predictions of the solute-vacancy interaction model for the effects of alloying elements on passivity breakdown.

(9) Development of a "point defect" model for the segregation of alloying elements into passive films.6,7 The predictions of the model are in accord with experimental segregation data obtained using a new technique, SALI (surface analysis by laser ionization), on dilute $\mathrm{Ni}$ $\mathrm{xAl}, \mathrm{Ni}-\mathrm{xTi}$, and $\mathrm{Ni}-\mathrm{xMo}(\mathrm{x}<8 \mathrm{wt} \%)$ alloys.

(10) Detection and explanation of photoinhibition of passivity breakdown as observed on nickel in buffered $\mathrm{KCl}$ solution. Photogeneration of electron/hole pairs apparently quenches the electric field in the passive film thereby reducing the driving force for the movement of cation vacancies from the film/solution interface to the metal/film interface. The lowered vacancy flux results in a positive shift in the breakdown voltage and hence in enhanced resistance to pitting.

(11) Extension of the Chao, Lin, and Macdonald theory for the impedance characteristics of passive films by incorporating kinetic effects caused by reactions involving vacancies at the metal/film and film/solution interfaces. ${ }^{8-11}$ We show that the impedance of passive nickel in phosphate buffer solutions ( $\mathrm{pH}=9-11$ ) at high frequencies ( $\mathrm{f}>100$ $\mathrm{Hz}$ ) is dominated by the kinetics of reactions occurring at the metal/film interface, whereas the impedance at low frequencies ( $f<1$ $\mathrm{Hz}$ ) is dominated by the movement of vacancies through the film. The mathematical techniques employed in this type of analysis are now being greatly improved and the method is now being used to analyze 
impedance data for passive tungsten, the passive film on which we have shown to be an oxygen ion conductor.

(12) Development of methods for measuring photoelectrochemical impedance functions for metal- and semiconductor-solution interfaces by modulating the intensity of an incident, monochromatic light beam and by transforming photocurrent transients from the time domain to the frequency domain. By using an $\mathrm{He} / \mathrm{Ne}$ laser with a photon energy of $1.96 \mathrm{eV}(632 \mathrm{~nm})$, we measured the photoelectrochemical impedance spectra for $\mathrm{n}-\mathrm{Si}$ and $\mathrm{p}-\mathrm{Si}$ in contact with sodium hydroxide solution over wide ranges of modulation frequency and applied bias potential. We are currently developing theoretical models to explain the impedance data in terms of the photogeneration of electron/hole pairs and their recombination via surface states, and in terms of the reactions of electrons and holes with redox species in the solution. More recently, we have greatly extended the photon energy range by using a square wave excitation function. Thus, we are now able to measure photoelectrochemical impedance spectra for wide bandgap passive films, such as those that form on tungsten and titanium.

(13) The use of Kramers-Kronig (K-K) transforms of electrochemical impedance spectroscopy (EIS) data to ascertain whether electrochemical systems satisfy the linearity, causality, and stability constraints imposed by linear system analysis. ${ }^{12-14}$ We continue to examine how well experimental EIS data transform according to the $\mathrm{K}-\mathrm{K}$ transforms by exploring one particular class of impedance functions known as constant phase impedances. We show unequivocally that constant phase impedances, which include those for passive films at low frequencies, transform provided that the loci are restricted to the right side of the complex plane. In a significant extension of this method, we have recently used the K-K transforms to explore the nature of the photoelectrochemical impedance function. We found that the function obeyed the transforms so that it may be regarded as a true impedance. Accordingly, the system response may be analyzed in terms of linear systems theory.

A central hypothesis of our theoretical work on the effect of alloying elements on passivity breakdown is that highly charged solutes, such as $\mathrm{Mo}^{6+}$ substituted into $\mathrm{NiO}$ passive films, form ion pairs with mobile cation vacancies of the type $\mathrm{Mo}_{\mathrm{Ni}}^{4 \cdot \ldots .} \mathrm{V}_{\mathrm{Ni}}^{2^{\prime}}$. This interaction is described as a chemical equilibrium using the Debye-Huckel and Onsager-Fuoss ionpairing theories, originally developed for aqueous electrolyte solutions but later used to describe vacancy-impurity interactions in semiconductors. This approach accounts very well for the effect of molybdenum on the pitting resistance of stainless steel and for the effects of $\mathrm{Al}, \mathrm{Ti}$, and Mo on the breakdown characteristics of nickel in buffered chloride solutions. The most effective alloying elements are those that

(1) Segregate to the greatest extent into the passive film (Mo $>\mathrm{Ti}>\mathrm{Al}$ ). 
(2) Possess the greatest charge relative to the host cation (i.e., $\mathrm{Mo}_{\mathrm{Ni}}^{4 \cdot}>$ $\left.\mathrm{Ti}_{\mathrm{Ni}}^{2 \cdot}>\mathrm{Al}_{\mathrm{Ni}}\right)$.

The extent of segregation was attributed principally to the high dielectric constant of the thin, electronically conducting passive film and hence to the ability of the film to "solvate" the substituted alloy solute. The magnitude of the charge is important because it determines the electrostatic energy of interaction with the negatively charged cation vacancies and hence the extent of ion-pair formation. However, these charges are also screened by oppositely charged entities (e.g., cation vacancies and electrons), and allowarce for this effect is made using the Debye-Hückel screening radius.

As noted above, photoinhibition of passivity breakdown, as observed in this program for nickel in buffered chloride solutions, is a direct manifestation of coupling between the electronic and lattice defect structures of the film. Because the films are highly doped with vacancies, which act either as acceptors $\left(\mathrm{V}_{\mathrm{M}}^{\chi \mathrm{x}}\right)$ or donors $\left(\mathrm{V}_{\mathrm{O}}^{* \bullet}\right)$, where $\chi$ is the oxide stoichiometry, $\left(\mathrm{MO}_{\chi / 2}\right)$, the model that emerges for the electronic structure of the film is that of a metal- $n^{+}-\mathrm{i}-\mathrm{p}^{+}$-solution junction with the relative $\mathrm{p}^{+}$and $\mathrm{n}^{+}$characters depending on the relative concentrations of metal and oxygen vacancies, respectively.

As with classically degenerate $n^{+}-i-p^{+}$junctions, the potential drop occurs entirely across the depletion region, with the electric field strength determined by the compensating processes of charge separation owing to isoenergetic tunneling from filled levels in the valence band to unfilled levels in the conduction band and electron/hole recombination, possibly via surface states. The photogeneration of electron/hole pairs quenches the electric field, thereby reducing the driving force for the transport of cation vacancies from the film/solution interface to the metal/film interface. Thus, incident light is expected to inhibit passivity breakdown, as observed experimentally. We are now exploring photoinhibition as a practical means of protecting equipment in the power generation industry from piting corrosion. This concept is being explored under an EPRI Exploratory Research grant.

The results of our previous studies are presented in the final report "Fundamental Studies of Passivity and Passivity Breakdown" which was submitted in October 1991 to DOE from SRI International. Accomplishments since then are summarized above or can be found in various papers that are listed at the end of this proposal. Additional work has been 
presented in various seminars and oral presentations at technical meetings as also listed in the Appendix.

\section{PROPOSED RESEARCH}

As a continuation of the work performed under Grant No. DE-FG02-91ER45461, we propose to investigate the physicoelectrochemical processes associated with the growth and breakdown of passive films on metal and alloy surfaces. The proposed work will consist of nine tasks:

\section{TASK 1. DERIVATION OF GROWTH RATE LAWS}

In our previous work, we solved the Nernst-Planck equations for the transport of cation and anion (oxygen) vacancies across a barrier (or primary) passive film (Figure 1), taking into account kinetic effects at the metal/film and film/solution interfaces. ${ }^{9-11}$ These solutions were obtained in Laplace space and later were substituted into a linearized expression for the interfacial current, followed by inverse transformation to yield the film impedance (see Performance Report).

By performing the inverse Laplace transform on the nonlinearized rate expression, we can derive the growth rate law to yield the time dependencies of the barrier film thickness and the current. By varying the relative values of the interfacial rate constants and the vacancy diffusivities, we should be able to simulate transients in film thickness and current that span the rate control spectrum from cation injection at the metal/film interface to vacancy transport across the film. Where possible, we will try to derive analytical expressions for the growth rate laws (probably by approximation), so that they may be compared directly with experimental data for the change in barrier film thickness and current with time, in response to a given potential perturbation (e.g., a potential step or potential sweep).

Experimental data for the transients in current and film thickness will be taken from the literature or will be measured as part of the current program. Transients in film thickness will be determined ellipsometrically using a rotating analyzer ellipsometer with a sampling frequency of $1 \mathrm{~Hz}$. 


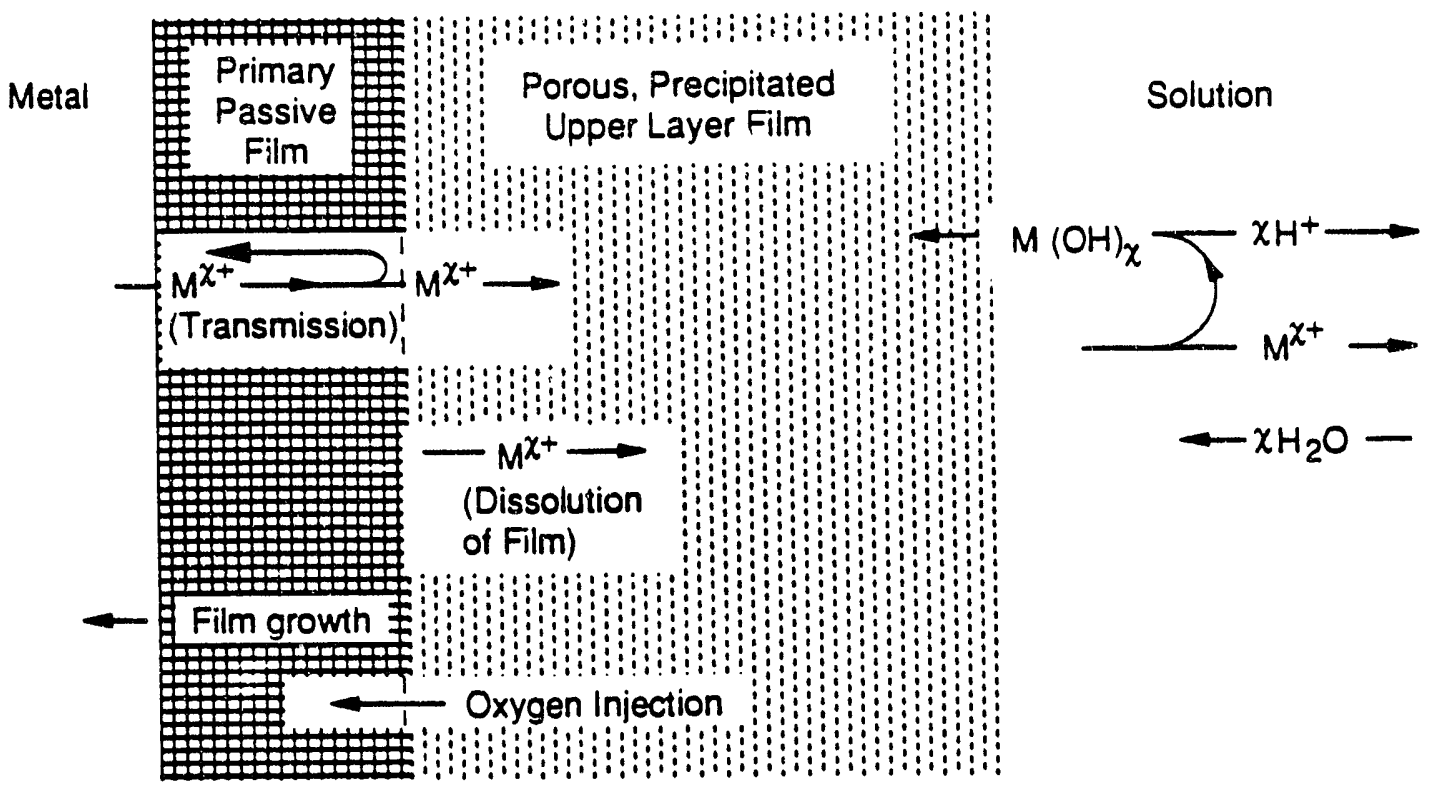

JA-M-7759-150A

Figure 1. Schematic of processes that lead to the formation of bilayer passive films on metal surfaces. 


\section{TASK 2. OXYGEN ION CONDUCTING FILMS}

To date, our work has concentrated on cation-conducting passive films such as $\mathrm{NiO}$ on $\mathrm{Ni}$. However, if the charge on the cation is high enough that cation vacancy generation is disfavored energetically, the ion current within the film is due to the movement of anion vacancies. Theory shows that, in this case, a steady state is achieved only when the rate of film growth at the metal/fiim interface is matched by the rate of barrier film dissolution at the film/solution interface, leading to a linear relationship between the film thickness and applied voltage (Figure 2 ). Furthermore, the passive current $\left(\mathrm{I}_{\text {SS }}\right)$ is predicted to vary with voltage $(\mathrm{V})$ according to the relationship

$$
\ln \left(\mathrm{I}_{\mathrm{sS}}\right)=\ln \left(\mathrm{I}_{\mathrm{sS}}^{\mathrm{o}}\right)+\alpha \alpha_{\mathrm{d}}(\delta-\chi) \gamma \mathrm{V}+\left[\beta \alpha_{\mathrm{d}}(\delta-\chi) \gamma-2.303 \mathrm{n}\right] \mathrm{pH}
$$

where $\gamma=F / R T, I_{s s}^{0}$ is a constant, $\alpha_{d}$ is a transfer coefficient for the film dissolution reaction, $\chi$ is the oxidation state of the cation in the film, $\delta$ is the corresponding quantity for the cation in solution, and $\alpha$ and $\beta$ are the dependencies of the voltage drop across the film/solution interface on the applied voltage and $\mathrm{pH}$, respectively. Accordingly,

$$
\left[\frac{\partial \ln \left(\mathrm{I}_{\mathrm{SS}}\right)}{\partial \mathrm{V}}\right]_{\mathrm{pH}}=\alpha \alpha_{\mathrm{d}}(\delta-\chi) \gamma
$$

and

$$
\left[\frac{\partial \ln \left(I_{s s}\right)}{\partial \mathrm{pH}}\right]_{v}=\beta \alpha_{d}(\delta-\chi) \gamma-2.303 n
$$

which may be used diagnostically to confirm anion transmission. Also after our previous work, we can estimate the electric field strength in the film by measuring the steady-state film thickness $\left(\mathrm{L}_{\mathrm{ss}}\right)$ as a function of applied voltage (Figure 1)

$$
\varepsilon=\frac{\left[1-\alpha-\frac{\alpha \alpha_{d}(\delta-\chi)}{2}\right]}{\left(\frac{\partial \mathrm{L}_{S S}}{\partial \mathrm{V}}\right) \mathrm{pH}}
$$

provided that estimates are available for $\alpha$ and $\alpha_{d}$ (or only $\alpha$ if $\delta=\chi$ ). 


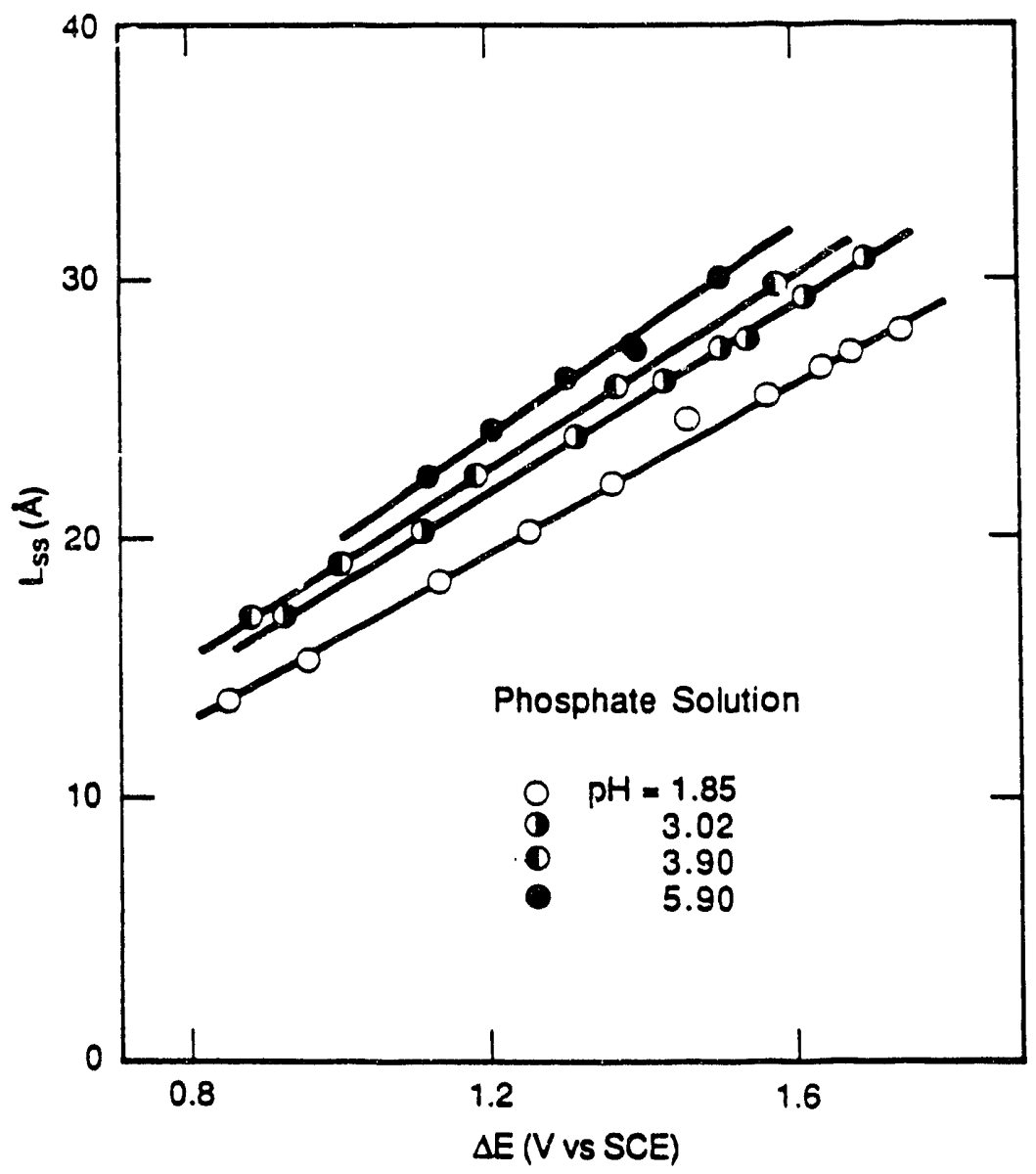

JA-7759-153

Figure 2. Thickness of the barrier oxide layer on iron in acidic phospilate solutions as a function growth potential.

(Atter Sato and Noda: soo Ret.1.) 
Finally, provided that the film/solution interface is in quasi-equilibrium with respect to oxygen ions and protons, the dependence $I_{S s}$ on the cation concentration in solution provides an unequivocal test of the theory

$$
\left[\frac{\partial \ln \left(I_{S S}\right)}{\partial \ln C_{M^{\delta+}}}\right]_{V, p H}=0
$$

Equation (5) is also predicted to hold for cation-conducting films when irreversible ejection of cations occurs at the film/solution interface. Indeed, using these diagnostic criteria we have demonstrated that the passive film on nickel is a cation conductor and that cation ejection at the film/solution interface is irreversible.

As noted above, anion (oxide)-conducting films are expected to form on metals that yield highly charged cations because the generation of cation vacancies is disfavored energetically (owing the high Coulombic contribution) relative to the formation of anion vacancies. Accordingly, our experimental studies on measuring the passive current and film thickness as a function of applied voltage and $\mathrm{pH}$ will be performed on "valve" metals such as titanium, zirconium, tungsten, and tantalum in acidic or basic environments, in which the passive films are expected to reach steady state in relatively short times. Our initial work on tungsten has confirmed the above prediction.

\section{TASK 3. VARIABLE VALENCE PASSIVE FILMS}

To date, we have developed theories that apply strictly to defective, single valence oxides such as $\mathrm{NiO}$. However, many barrier passive films contain cations of more than one oxidation state, such as that on iron where the average oxidation state of the cation varies from 2 at the metal/film interface to a maximum of 3 at the film/solution interface. In these cases, the transport of vacancies across the barrier layer will be described by modified forms of the Nernst-Planck equation, such as

$$
\frac{\partial \mathrm{C}_{O}}{\partial \mathrm{t}}=\mathrm{D}_{\mathrm{O}} \frac{\partial^{2} \mathrm{C}_{\mathrm{O}}}{\partial \mathrm{x}^{2}}-2 \mathrm{KD} O\left(\frac{\partial \mathrm{C}_{O}}{\partial \mathrm{x}}\right)
$$




$$
\frac{\partial C_{M}}{\partial t}=D_{M} \frac{\partial^{2} C_{M}}{\partial x^{2}}+g(x) K D_{M}\left(\frac{\partial C_{M}}{\partial x}\right)
$$

where subscripts $O$ and $M$ designate oxygen and metal vacancies, respectively, and $g(x)$ is a function that describes the change in cation valence with distance through the film. In this work, we propose to extend the point defect theories for the steady-state properties of passive films, the impedance characteristics, the electronic stuctures, and the photoelectrochemical response to variable valence passive films and to assess the theories using experimental data developed in this work or taken from the literature. We will also extend the point defect and solute vacancy interaction models for passivity breakdown to variable valence barrier films in an attempt to account for an enormous body of data that exists in the literature on the pitting of iron and $\mathrm{Fe}-\mathrm{Cr}$ and $\mathrm{Fe}-\mathrm{Cr}$ - $\mathrm{Ni}$ alloys.

\section{TASK 4. ELECTROCHEMICAL IMPEDANCE SPECTROSCOPY}

During this past reporting period, we developed a comprehensive treatment for the electrochemical impedance characteristics of passive nickel. The model (Figure 3) included vacancy transport across the film coupled to vacancy generation and annihilation at the metal/film and film/solution interfaces. We showed that a cation vacancy conduction mechanism is more consistent with the experimental data for passive nickel than is an oxygen vacancy mechanism and that the impedance is insensitive to the processes that occur at the film/solution interface at experimentally accessible frequencies. However, we also found (Figure 4) that the impedance spectrum at high frequencies $(>100 \mathrm{~Hz})$ is sensitive to the kinetics of vacancy generation and annihilation at the metal/film interface and that the low-frequency region of the impedance spectrum is dominated by cation vacancy transport across the film.

In our current work, we extended the frequency range down to $10^{-4} \mathrm{~Hz}$, and we are exploring the feasibility of impedance measurements at even lower frequencies with the goal in mind of detecting vacancy generation and annihilation at the film/solution interface. However, it is extraordinarily difficult to obtain reliable data at frequencies in the $10^{-3}$ to $10^{-4} \mathrm{~Hz}$ range because of system instability. 
Metal

Barrier Film

Solution

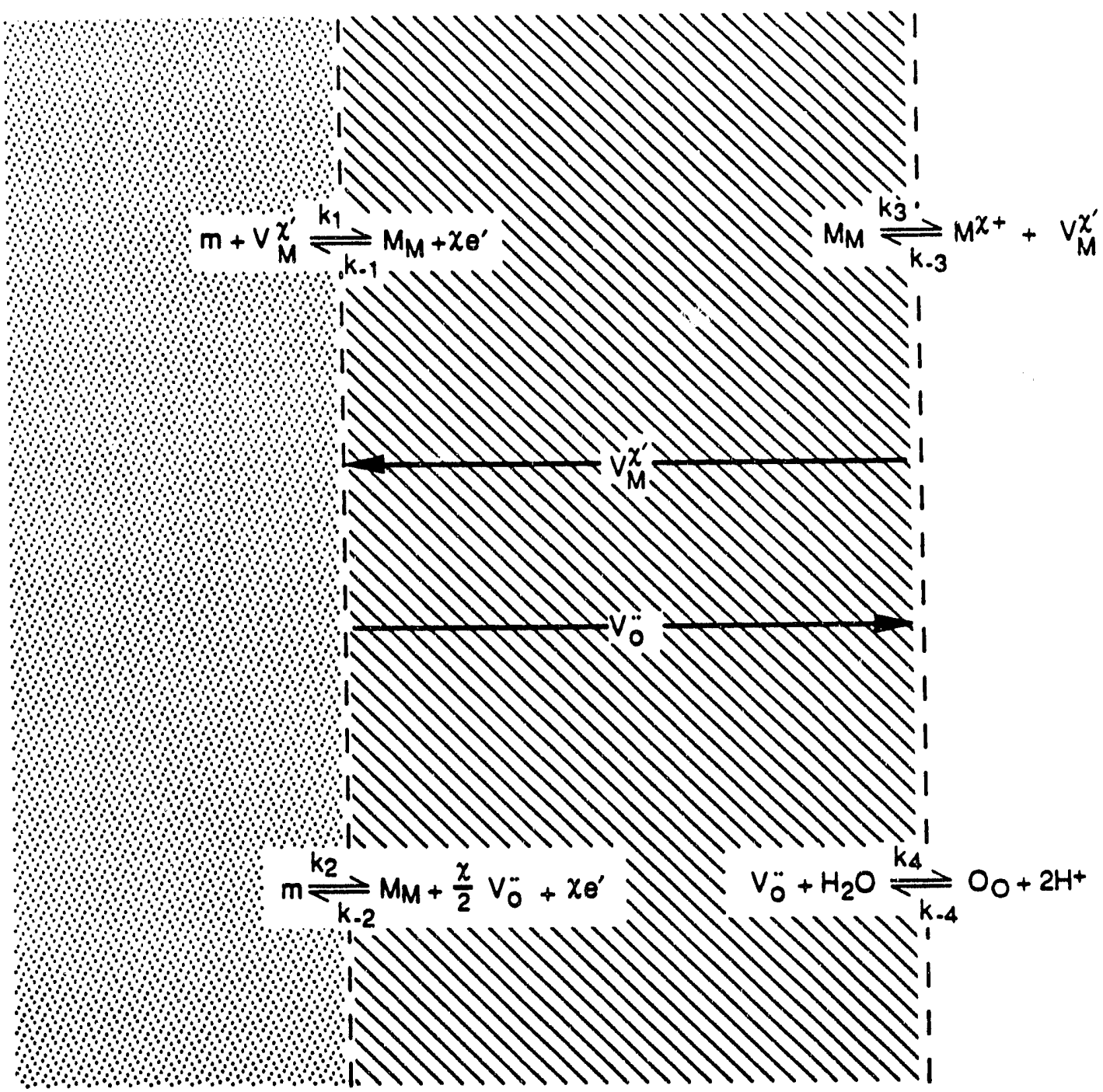

\section{Metal/Film \\ intertace}

$$
x=0
$$

Film/Solution

Interiace

$X=L$

RA-M-7759-18

Figure 3. Schematic of vacancy transport processes and interfacial reactions that occur in a barrier passive film. 
To ensure the validity of measured impedance data, we will use the Kramers-Kronig transforms to test for compliance of the system (passive nickel) with the linearity, stability, and causality constraints for linear systems. To our knowledge, we are still the only laboratory that uses the $\mathrm{K}-\mathrm{K}$ transforms on a regular basis to test the quality of impedance data. This capability was made possible by our developing practical algorithms a number of years ago for performing K-K transforms on electrochemical impedance data.

We propose to continue our impedance studies on passive nickel at submillihertz frequencies to characterize the kinetics of cation injection into and cation vacancy transport across the passive film on this metal as a function of potential and $\mathrm{pH}$, in an attempt to detect reactions involving vacancies at the film/solution interface. We also propose to extend these studies to oxygen ion-conducting films such as those that form on "valve" metals like $\mathrm{Ti}, \mathrm{Zr}$, and $\mathrm{Ta}$. The experimental data will be used to guide development of the theoretical model by using a generalized nonlinear regression algorithm (OPTDES) to fit the theoretical impedance to experiment and hence to derive numerical values for important model parameters. We used OPTDES in our current studies to fit the point defect model to experimental impedance data for passive nickel (e.g., Figure 4). This procedure has proved extremely powerful; as many simultaneous equations as necessary may be generated (at different frequencies) to determine the unknown parameters in the model. We propose to generalize this procedure by fitting the models to experimental data over segments of frequency and ultimately over the whole frequency range to determine the optimum set of kinetic and transport parameters for cation- and anion-conducting passive films on various metals.

\section{TASK 5. ELECTRONIC STRUCTURES OF PASSIVE FILMS}

In our current studies, we regarded passive films as highly but nonlinearly doped semiconductors with oxygen vacancies and cation vacancies acting as donors and acceptors, respectively. Indeed, the closest classical electronic analog to the passive film on nickel appears to be a $\mathrm{n}^{+}-\mathrm{i}-\mathrm{p}^{+}$tunnel junction, in which the principal dopant is the cation vacancies, giving the film an overall p-character. Our preliminary studies on solving Poisson's equation for nonlinearly doped structures demonstrated that interpreting the photoelectrochemical properties of passive films in terms of the classical Mott-Schottky theory is invalid, because the nonlinear doping profiles lead to electronic properties that 

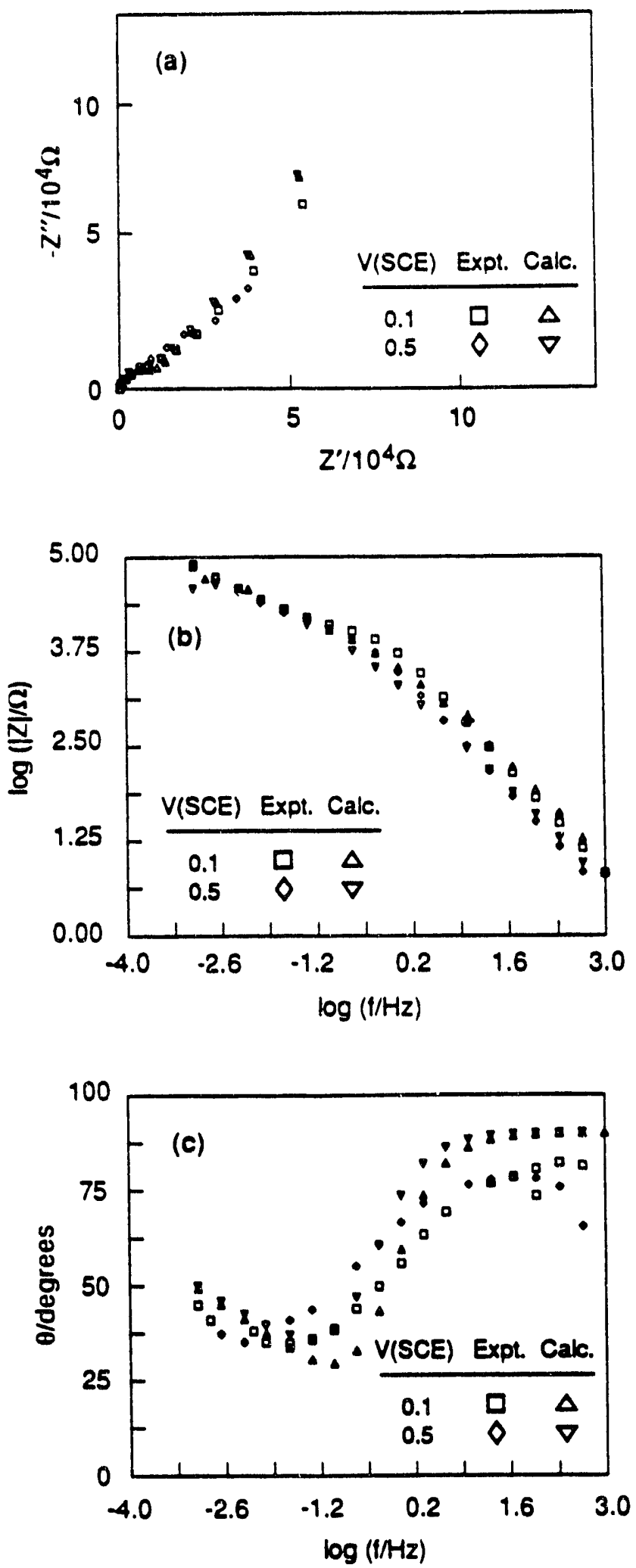

RA-7752-20

Figure 4. Experimental and calculated impedance data for $\mathrm{Ni}(\mathrm{III})$ in $0.1 \mathrm{~N}$ $\mathrm{H}_{3} \mathrm{PO}_{4} / \mathrm{NaOH}$ butfer solution, $\mathrm{pH}=10$, at $23 \pm 2^{\circ} \mathrm{C}$ assuming that cation vacancies alone are mobile in the barrier film.

(a) -Z' vs $Z^{\prime}$, (b) $\log |Z|$ vs $\log ($ (f), (c) 0 vs $\log ($ (f). 
cannot be interpreted in terms of abrupt junction or linearly-graded junction theory, even though that has been tried on numerous occasions in photoelectrochemical studies.

To date, we have solved Poisson's equation for exponentially graded junctions (modeling passive films) by assuming that the system is not degenerate. However, the concentrations of vacancies in passive films are very high (typically up to $10^{19}-10^{20} \mathrm{~cm}^{-3}$ ), at least close to the interfaces, so that the electronic structure is almost certainly degenerate. Accordingly, we propose to extend our current studies by solving Poisson's equation for the degenerate case to yield the potential distribution across the barrier film as a function of applied voltage (and hence thickness), $\mathrm{pH}$, and other system parameters and variables. Once this has been done, we will derive the tunneling probability for electron transfer to compare theory with experiment for the kinetics of redox reactions at passive interfaces.

Electron transfer studies will be performed on passive nickel and titanium in aqueous solution containing a suitable redox couple [e.g., $\left.\mathrm{Fe}(\mathrm{CN})_{6}^{4-/ 3-}\right]$. The electrodes will be prepassivated by growing passive films in solutions without the redox couple, and the exchange current density and transfer coefficients for charge transfer across the film will be measured using rotating disk voltametry and electrochemical impedance spectroscopy. The high-frequency performance of the latter technique will be optimized by using a very low impedance reference electrode formed by capacitively coupling a platinum wire in parallel with the calomel electrode.

\section{TASK 6. PHOTOELECTROCHEMICAL ADMITTANCE SPECTROSCOPY (PAS)}

In our current work, we explored the feasibility of modulating the intensity of incident light as a means of probing the electronic structures of passive films. We did this by comparing the modulated current output $[\mathrm{I}(j \omega)]$ with the sinusoidal light intensity $[\mathrm{J}(j \omega)]$ to derive the photoelectrochemical admittance

$$
\mathrm{Y}_{\mathrm{pH}}=\mathrm{I}(\mathrm{J} \omega) / \mathrm{J}(\mathrm{j} \omega)
$$

or impedance $(\mathrm{Z}=1 / \mathrm{Y})$, where $\omega$ is the frequency of modulation and $\mathrm{j}$ is the complex variable $(j=\sqrt{-1})$. To date, we have used this technique to probe the electronic structures of $n$ - and $\mathrm{p}-\mathrm{Si} / \mathrm{NaOH}$ interfaces at modulation frequencies from $50 \mathrm{kHz}$ down to $\sim 1 \mathrm{~Hz}$ (Figure 5). We demonstrated that the admittance data obey the Kramers-Kronig transforms (the first time this has ever been done), so the data can be interpreted in terms of linear 

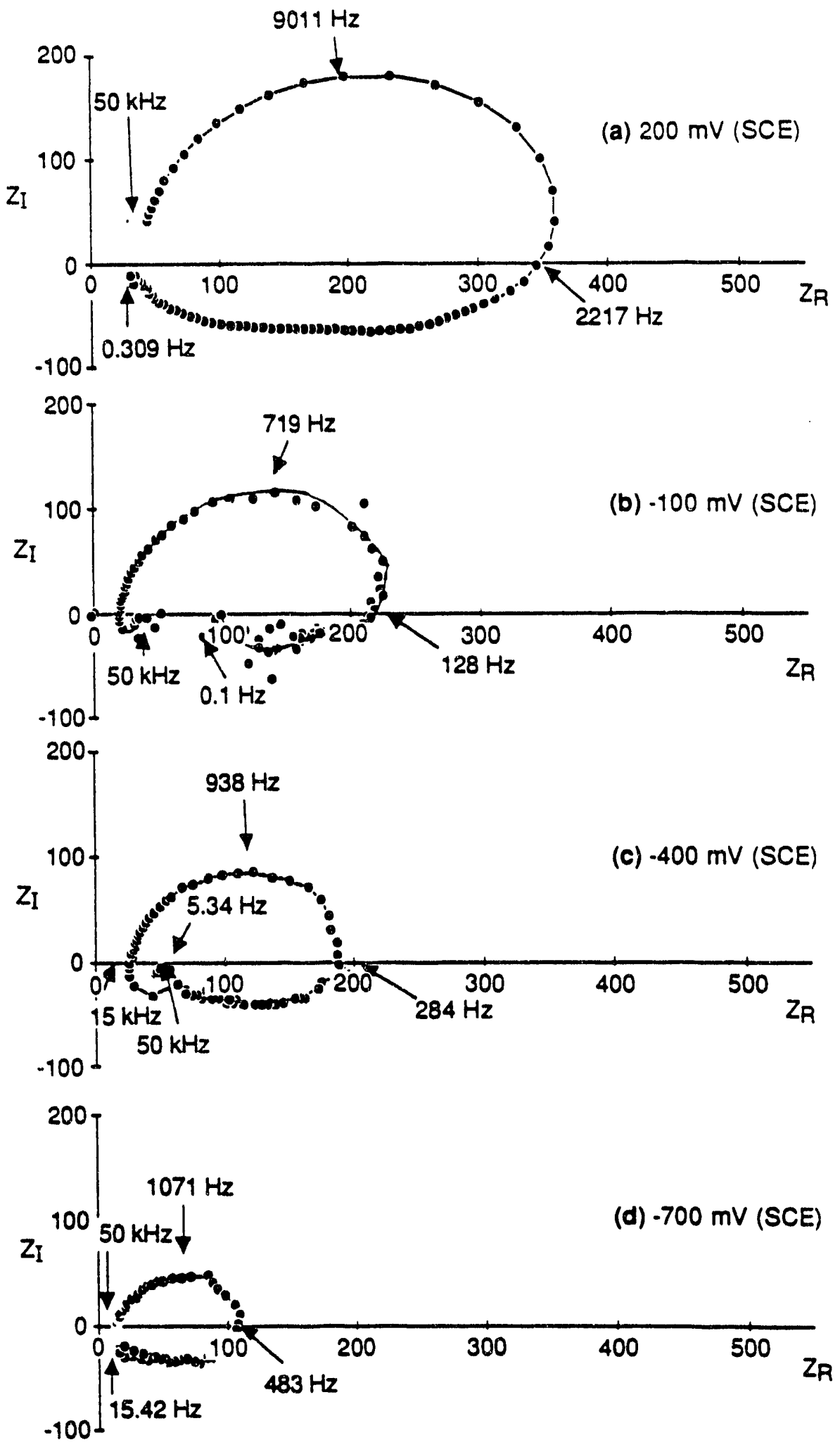

RA-350525-17

Figure 5. Photoimpedance spectra for $n-S i$ in $1.0 \mathrm{M} \mathrm{KOH}$ at $25^{\circ} \mathrm{C}$, $\lambda=632.8 \mathrm{~nm}$. 
systems theory. Later, we developed a model involving photogeneration of electron/hole pairs and their recombination via surface states, and reaction of the electrons and holes with redox species in solution. This model successfully explains the frequency dispersion of the measured admittance. From these studies we concluded that the surface states at the film/solution interface are probably oxygen and cation vacancies.

The studies outlined above showed PAS to be an extraordinarily powerful experimental technique because of the very wide range over which the modulation frequency may be varied. We believe, however, ihat PAS will become an even more powerful analytical tool by varying the photon energy, so that band-to-band and subband gap transitions can be activated and explored in a systematic manner.

The studies outlined above were performed using a He-Ne laser $(\lambda=632.8 \mathrm{~nm})$, the intensity of which is modulated using an acousto-optic coupler driven by the reference signal from the SOLARTRON Frequency Response Analyzer that is also used to measure the admittance (see Experimental and Analytical Techniques Section). In this configuration, we cannot vary the photon energy readily over the range of interest for most passive films (e.g., hv $=1.5$ to $3 \mathrm{eV}$ ), simply because the acousto-optic couplers do not operate efficiently in this range and inexpensive lasers are not available with the photon energies of interest.

Accordingly, we developed a Laplace transform technique for determining the photoelectrochemical admittance (or impedance) from the photocurrent transient in response to a stepped increase in light intensity. In this case, we can to use a quartz lamp/monochromator as a light source, with photon energies ranging from the infrared to the ultraviolet and a mechanical shutter to generate a stepped change in light intensity. Thus, we can now probe passive films that form on metals such as $\mathrm{Ni}, \mathrm{Ti}, \mathrm{Fe}$, and $\mathrm{Cr}$ using PAS as a function of applied voltage and photon energy. To our knowledge, we are the first laboratory to accomplish this goal.

We propose to extend our PAS studies to $\mathrm{Ni}, \mathrm{Fe}, \mathrm{Cr}$, and $\mathrm{Ti}$ in aqueous solutions as a means of probing the kinetics of electron/hole pair generation and recombination in passive films on these metals. These studies will be performed as a function of applied voltage to 
vary the film thickness and density of surface states (assuming the surface states to be .oxygen and cation vacancies) and in the presence of redox couples, such as $\mathrm{Fe}(\mathrm{CN})_{6}^{3-/ 4-}$, to react with photogenerated electrons and holes, depending on the voltage bias applied to the system. We will also continue our development of kinetic models for the photoelectrochemical behavior of passive electrodes, and we will use a general nonlinear regression technique (e.g., OPTDES) to obtain kinetic parameters from the admittance data. Our PAS data will continue to be tested for compliance with the linearity, stability, and causality constraints of linear systems theory using the Kramers-Kronig transforms.

\section{TASK 7. KINETICS OF LOCALIZED ATTACK}

In our previous work under DE-FG03-84ER45164, we derived theoretical distribution functions for the critical voltage and induction time the breakdown of passive films on metal surfaces (Figures 6 and 7, respectively). We tested these functions experimentally and found them to account very well for the nucleation of pits on nickel and on $\mathrm{Ni}-\mathrm{Al}, \mathrm{Ni}$ $\mathrm{Ti}$, and $\mathrm{Ni}$-Mo alloys in sodium chloride solution, as determined in our laboratory, and for similar data reported in the literature for $\mathrm{Fe}-\mathrm{Cr}-\mathrm{Ni}$ alloys. The theory for passivity breakdown was extended to account for the role of minor alloying elements in determining the susceptibility of an alloy to pitting attack, and the derived breakdown voltage at the 50th percentile was found to account for the available experimental data on the effect of molybdenum on the pitting susceptibility of Fe- $\mathrm{Cr}$ alloys in chloride solutions in a semiquantitative manner (Figure 8).

The same theory was also used to account for the segregation of alloying elements into passive films (Figure 9), as determined using surface analysis by laser ionization (SALI). As a result of these studies, we formulated a set of "rules" for designing niew pit-resistant alloys in terms of the properties of the host cation and the alloying element cation in the film. Accordingly, the theoretical development of the point defect model, as it relates to passivity breakdown, is essentially complete. However, our ultimate objective is to develop a sound theoretical understanding of the factors that determine the damage function for localized corrosion (i.e., the distribution in pit depth as a function of time). To do this, we must develop a physically realistic model for pit growth that can be combined with the nucleation theory outlined above to describe the damage function. 


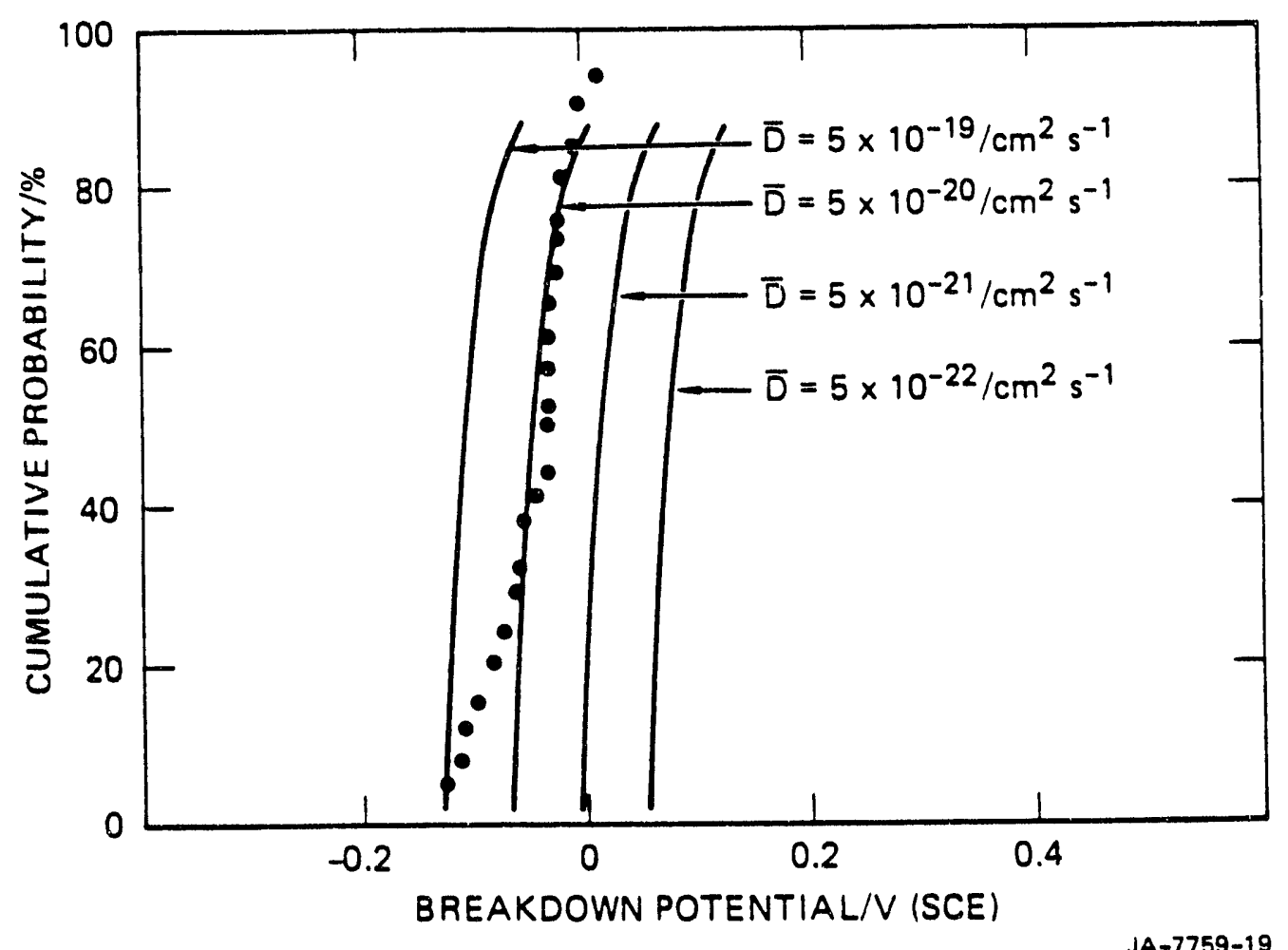

Figure 6. Cumulative probabilities for the breakdown voltage as a function of $\bar{D}$ for normal distributions in the diffusivity $D$.

$\beta=0.01, \sigma_{D}=0.75 \bar{D}, T=298.25 \mathrm{~K}, a_{y}=0.402, \chi=3$.

- Data for $\mathrm{Fo}-17 \mathrm{Cr}$ in $3.5 \% \mathrm{NaCl}$ solution at $30^{\circ} \mathrm{C}$ from Shibata (seo Rols. 2 and 3).

$\bar{V}_{c}=-0.046 \vee(S C E)$. 


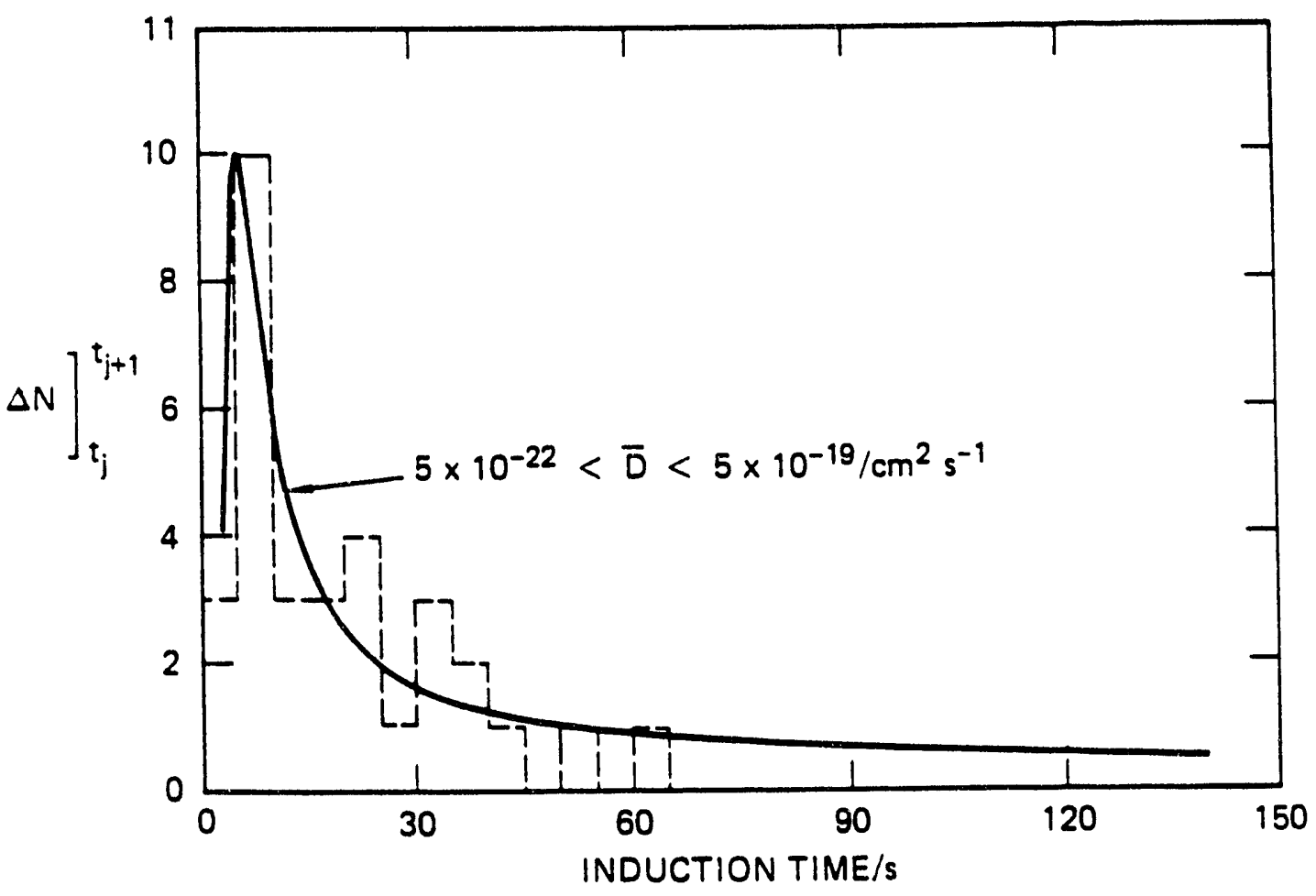

Figure 7. Differential cumulative probabilities for the induction time as a function of $\bar{D}$ for normal distributions in $D$.

$\sigma_{D}=0.75 \bar{D}$. (- - ) Data for $\mathrm{F}-17 \mathrm{Cr}$ in $3.5 \% \mathrm{NaCl}$ solution at $30^{\circ} \mathrm{C}$ from Shibata (se0 Refs. 2 and 3), $\bar{v}_{c}=-0.046 V(S C E), V=0.020 V(S C E), \bar{\tau}-7.5 \mathrm{~s}, \tau=0$. 


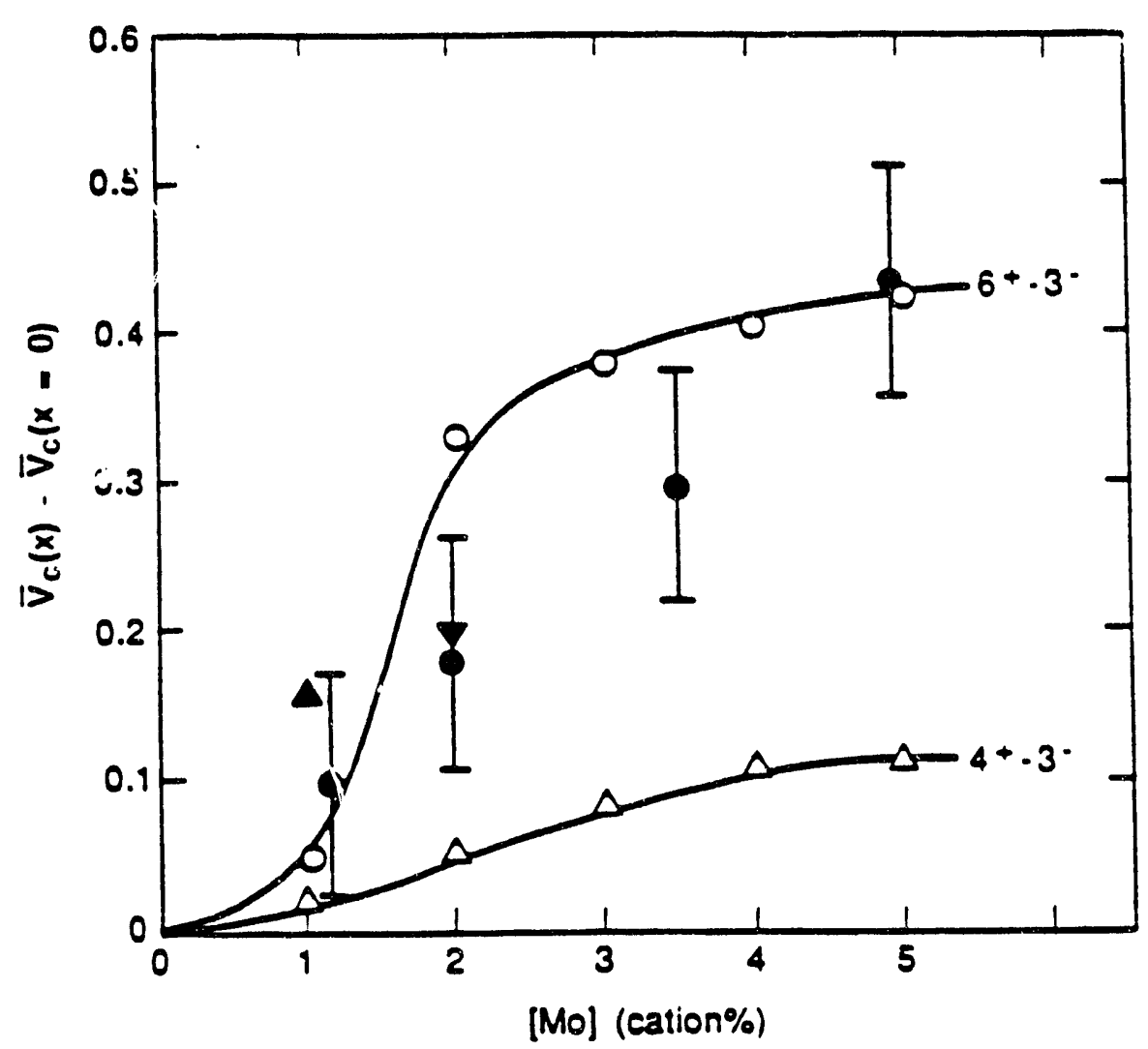

Figure 8. Effect of molybdenum concentration on $\bar{V}_{c}(x)-\bar{V}_{c}(x=0)$ for $5^{+}-3^{-}(O)$ and $4^{+}-3^{-}(\Delta)$ complexes in the passive film on Fe-Cr-Ni-XMo alloys.

$n_{v}=5 \times 10^{20} \mathrm{~cm}^{-3}, K_{1}=1.13 \times 10^{-16} \mathrm{~cm}^{3}(O)$

$K_{1}=1.13 \times 10^{-16} \mathrm{~cm}^{3}(\Delta)$.

- Liebus and Bond: Fo-18 Cr in $1 \mathrm{M} \mathrm{NaCl}$ at $25^{\circ} \mathrm{C}$

$\Delta$ Shibata: $\mathrm{Fo}-17 \mathrm{Cr}$ in $3.5 \% \mathrm{NaCl}$ at $30^{\circ} \mathrm{C}$

$\nabla$ Shibata: $\mathrm{Fo}-18 \mathrm{Cr}$ in $3.5 \% \mathrm{NaCl}$ at $30^{\circ} \mathrm{C}$

(Soo Rot. 4.) 


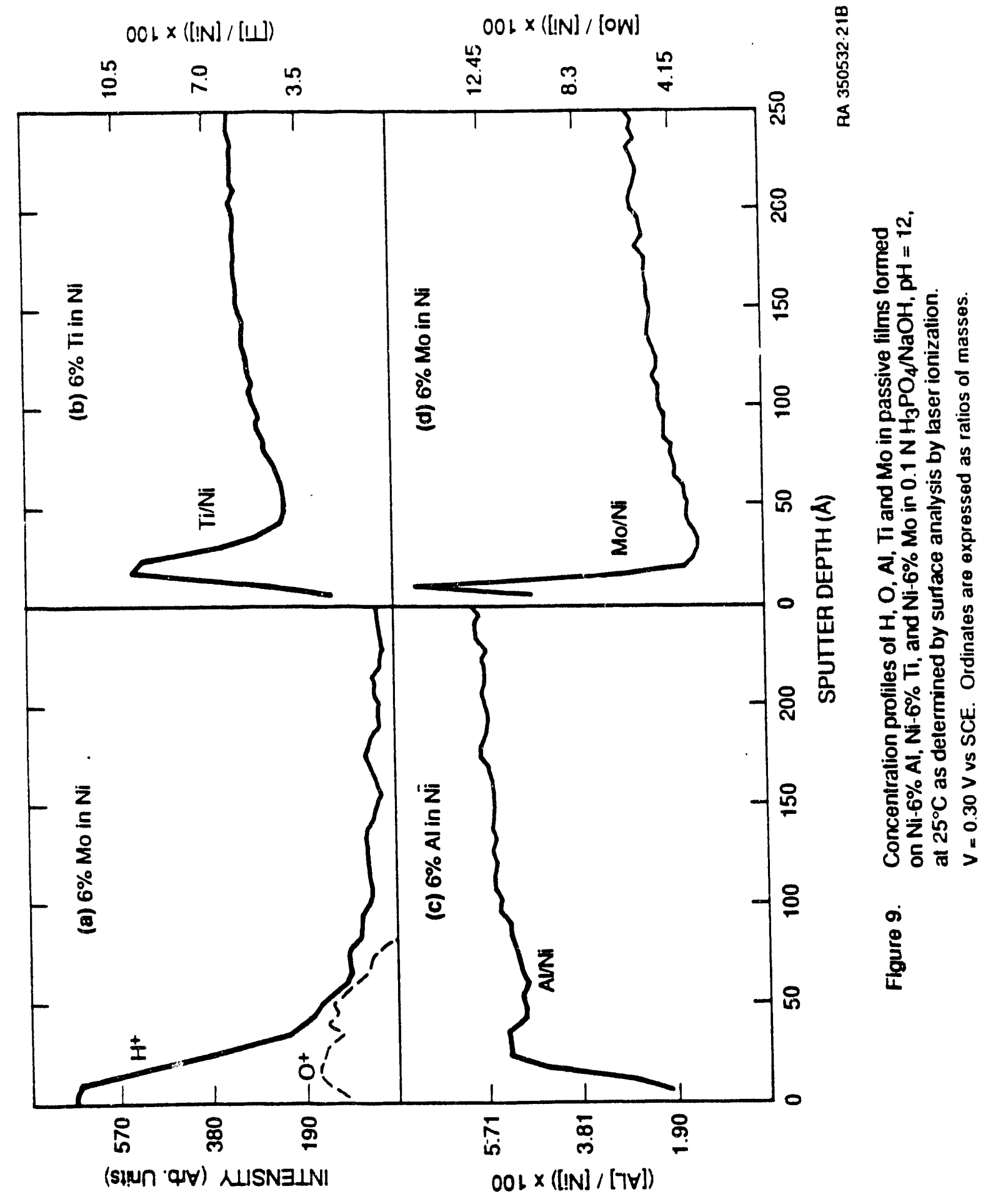


Recently we developed the Coupled Environment Fracture Model (CEFM) ${ }^{15}$ to describe intergranular stress corrosion cracking (IGSCC) in sensitized Type 304 SS in nuclear reactor heat transport systems (Figure 10). This work, supported by the Swedish Nuclear Power Inspectorate, resulted in a model in which the processes occurring in the crevice (crack) are coupled mathematically to oxygen reduction on the external surface through the condition for charge conservation

$$
i_{\text {crack }} A_{\text {crack }}+\int_{S} i_{c} d S=0
$$

where $i_{\text {crack }}$ is the current density at the crack mouth of area $A_{\text {crack }}, i_{c}$ is the current density for oxygen reduction on the external surface, and $\mathrm{dS}$ is an increment of area. Equation (9) was solved numerically to yield the potential distribution down the crack and the current and potential distributions across the external surface away from the crack mouth by alternately solving Laplace's equation for the crack and external environment, using as boundary conditions the Butler-Volmer equations for metal electrodissolution at the crack tip and oxygen reduction on the external surface. The CEFM has been found to provide a deterministic account of crack propagation in reactor heat transport environments.

We propose to modify the CEFM in this work to describe pit growth in metals and alloys by modifying the slip dissolution model for the crack tip processes to account for dissolution at the base of a pit in the absence of stress. Kinetic data for the reactions at the pit base for iron, nickel, chromium and $\mathrm{Fe}-\mathrm{Cr}-\mathrm{Ni}$ alloys in sodium chloride solutions will be obtained using artificial pits formed by sealing wires into plastic. We propose to obtain the kinetic data using electrochemical impedance spectroscopy and transient electrochemical techniques.

The theories for pit nucleation (developed under the previous contract) and pit propagation (described above) will be combined to provide a deterministic model for the damage function (i.e., of the distribution in pit depth as a function of time; Figure 11). Software will be prepared so that the model can be fitted to experimental damage functions by varying certain parameters or groups of parameters in an optimization procedure using the commercial algorithm OPTDES, which we will also use in Tasks 5 and 6 to analyze impedance data. Our ultimate objective is to derive a theory for predicting the lifetimes of 


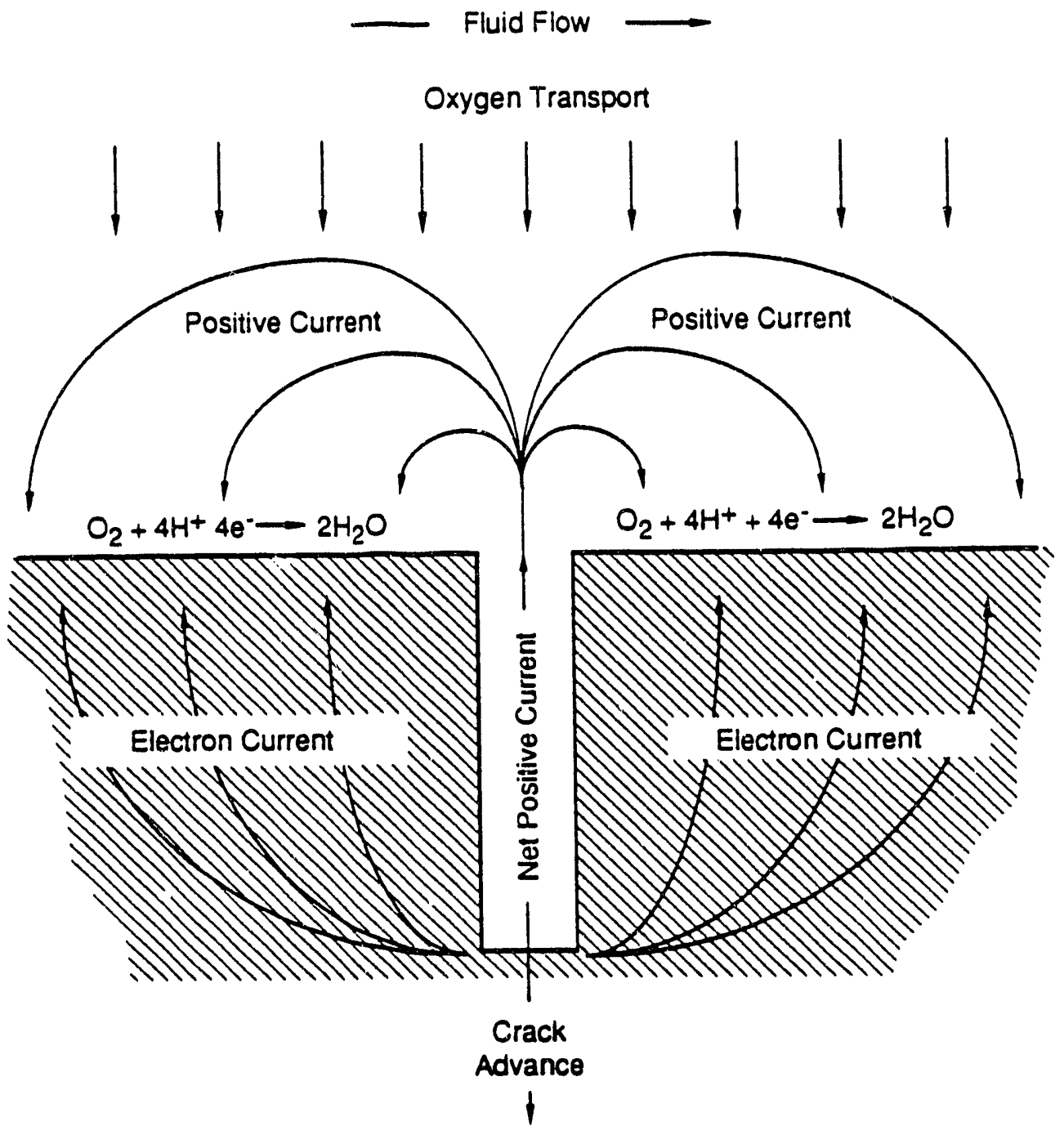

RA-M-4032-23

Figure 10. Coupling of the intemal and external environments of a stress corrosion crack by oxygen reduction on the external steel surfaces. 


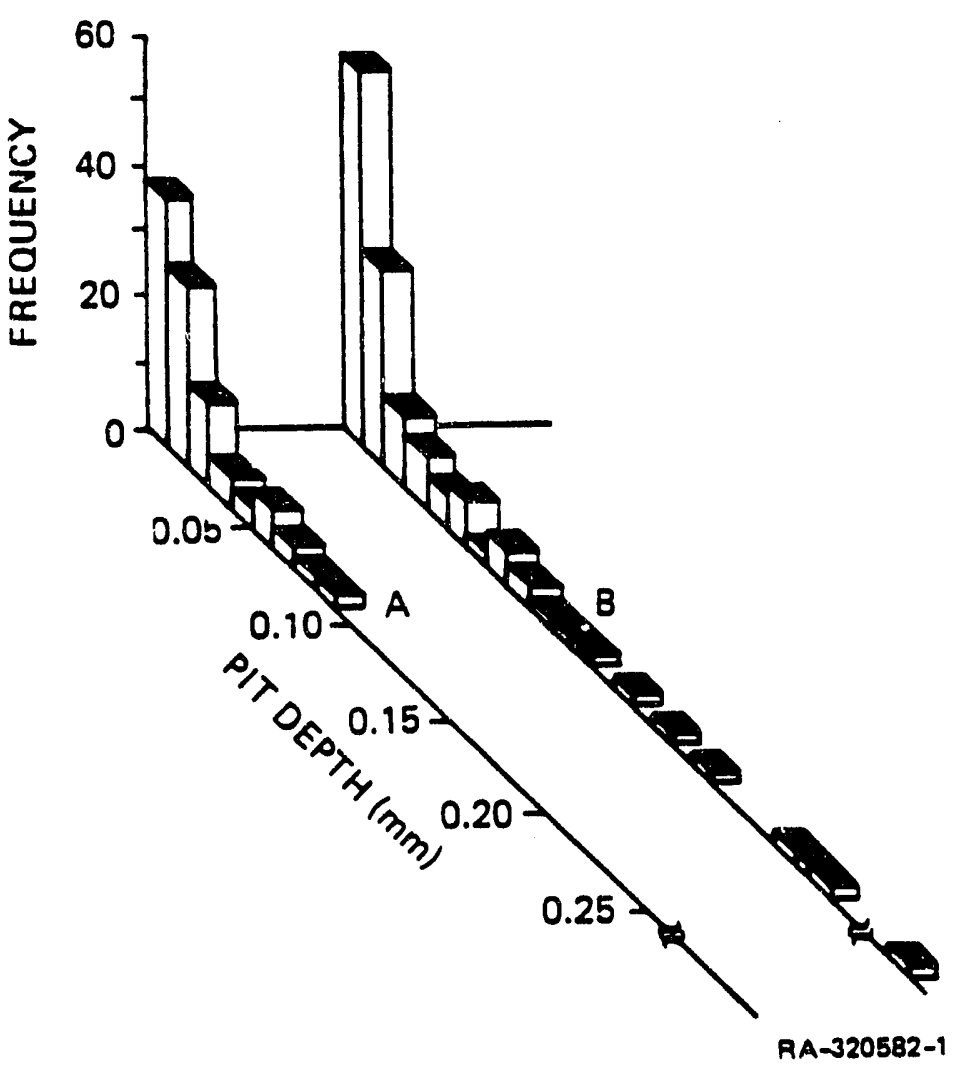

Figure 11. Pit depth distributions for Type 403 stainless steel exposed to soil. (After Ishikawa et al. ${ }^{16}$ )

A - Initial distribution.

B - Atter tive years. 
components (e.g., condenser tubes, storage tanks, pipelines) that are subject to pitting corrosion.

\section{TASK 8. EXPERIMENTAL DAMAGE FUNCTIONS}

In this task, we propose to experimentally measure damage functions for pitting on iron, nickel, chromium, and $\mathrm{Fe}-\mathrm{Cr}-\mathrm{Ni}$ alloys in buffered sodium chloride solutions to provide a data base for evaluating the theoretical work to be performed in Task 8 . Briefly, damage functions will be measured by exposing metal and alloy specimens at preselected potentials to chloride-containing solutions for various time periods. After removal, the surfaces will be milled away by predetermined amounts and the remaining pits will be counted to yield directly the distribution in pit depth. We envisage exposing specimens for periods of several months to nucleate a large enough number of pits and to grow them to sufficient depths to render the statistics reliable.

The type of data we expect from these studies are similar to those shown in Figure 11. Most pits are relatively shallow and only a few appear in the deep penetration end of the spectrum. However, these are the pits that lead to failure, so that describing the distribution function accurately at the extremes is most important . Accordingly, we will use appropriate weightings of the extreme values when fitting the model developed in Task 7 (using OPTDES), bearing in mind that the data at the extremes are also the least significant from a statistical viewpoint.

\section{TASK 9. DESIGN OF NEW ALLOY SYSTEMS}

During the past reporting period we developed a deterministic model fo: pit nucleation that relates the distribution functions in breakdown voltage $\left(\mathrm{V}_{\mathrm{c}}\right)$ and induction time (tind) to the composition of the alloy and the properties of alloying species in the passive film (e.g., Figure 8). For example, an effective alloying element for inhibiting pitting attack, according to the theory, is one that preferentially segregates into the passive film and forms a substitutional (immobilized) solute of high charge that can interact electrostatically with mobile cation vacancies to form solute/vacancy "ion pairs."

This model explains very well the experimental distribution functions for $\mathrm{V}_{\mathrm{c}}$ and $\mathrm{t}_{\text {ind }}$ for the binary alloys $\mathrm{Ni}-x \mathrm{Al}, \mathrm{Ni}-\mathrm{xTi}$, and $\mathrm{Ni}-\mathrm{xMo}(0.05<\mathrm{x}<8 \mathrm{wt} \%)$, in which the order of increasing effectiveness of the alloying element for pit inhibition was found to be $\mathrm{Al}<\mathrm{Ti}<$ 
Mo, corresponding to the formation of $\mathrm{Al}_{\mathrm{Ni}}^{\bullet}, \mathrm{Ti}_{\mathrm{Ni}}^{2 \cdot}$, and $\mathrm{Mo}_{\mathrm{Ni}}^{4 \cdot}$ in the passive film. We also - . expect that our activities in Task 7 will produce a similarly deterministic relationship between alloy composition and kinetics of pit growth, so that the combined theory could be used to design new alloy systems. 
APPENDIX A 


\section{GRADUATE STUDENTS}

The following graduate students are currently participating in this research program.

\begin{tabular}{llcc}
\multicolumn{1}{c}{ Name } & Department & $\begin{array}{c}\text { Degree } \\
\text { Sought }\end{array}$ & $\begin{array}{c}\text { Anticipated Completion } \\
\text { Date }\end{array}$ \\
\hline David Ellerbrock & Materials Science \& Engrg. & Ph.D. & $6 / 95$ \\
Lei Zhang & Materials Science \& Engrg. & Ph.D. & $6 / 94$ \\
Masahiro Yoshimoto & Engineering Sci. \& Mechanics & M. S. & $12 / 92$
\end{tabular}

Assuming the budgeted level of support, we anticipate the appointment of one additional graduate student to the program in the fall of 1992.

\section{Post-Doctoral Fellow:}

Currently, the PDF supported on this program is Dr. Albert Goossens, who came to Penn State University in September 1991 from The Netherlands. Dr. Goossens will leave Penn State in July of 1992 to assume a position at The University of California at Berkeley. At that time, Dr. Elizabeta Sikora from The Polish Academy of Sciences will join the program as a post doctoral fellow to continue the work started by Dr. Goossens. 


\section{PUbLICATIONS AND PRESENTATIONS}

1. D. D. Macdonald, "Application of Electrochemical Impedance Spectroscopy in Electrochemistry and Corrosion Science," Techniques for Characterization of Electrodes and Electrochemical Processes, Eds. Ravi Varma and J. R. Selman, Copyright 1991 by John Wiley \& Sons, Inc., p. 515-580.

2. D. D. Macdonald, "Probing (and Understanding?) the Passive State," presented at Fall Mtg. of Electrochemical Soc. in acceptance of the Carl Wagner Award, Phoenix, AZ, October 13-18, 1991. Proc. Symp. Crit. Factors Local. Corros. (Ed. G. S. Frankel and R. C. Newman), Vol. 92-9, p. 1 (1992).

3. D. D. Macdonald, "On the Viability of Hydrogen Water Chemistry for Protecting InCore Components of Boiling Water Reactors. I. Calculation of Electrochemical Potential from Radiolysis Data," Corrosion, in press (1992).

4. D. D. Macdonald and M. Urquidi-Macdonald, "An Advanced Coupled Environment Fracture Model for Predicting Crack Growth Rates," to be published in TMS Proceedings, Parkins Symposium on Fundamental Aspects of Stress Corrosion Cracking, Cincinnati, OH, October 20-24, 1991.

5. D. D. Macdonald, "Calculation of Corrosion Potentials in Boiling Water Reactors," Corrosion, submitted :991. Presented at the 5th Symposium on Environmental Degradation of Materials in Nuclear Power Systems -- Water Reactors, Monterey, CA, Sept. 1991. To appear in "Proc. 5th Int. Symp. Environ. Degrad. Mat. Nucl. Power Systs. -- Water Reactors," ANS/NACE, in press (1991).

6. D. D. Macdonald and M. Urquidi-Macdonald, "An Advanced Coupled Environment Fracture Model for Predicting Crack Growth Rates in LWR Heat Transport Circuits," Proc. Fifth Int. Symp. Environ. Degrad. Mat. Nucl. Power Syste. - Water Reactors, ANS/NACE, in press (1991).

7. P. C. Searson, H. Song, and D. D. Macdonald, "Transient Impedance Analysis of Photoprocesses at Illuminated Seminconductor Electrodes," submitted to J. Electrochem. Soc., 1991.

8. D. D. Macdonald, "The Point Defect Model for the Passive State," (from paper delivered in acceptance of the Carl Wagner Award at the Fall Meeting of the Electrochemical Society, Phoenix, AZ, October 13-18, 1991), submitted to J. Electrochem. Soc., 1992.

9. D. D. Macdonald, "Estimation of Corrosion Potentials in the Cores of Light Water Reactors," to be presented at Corrosion/92, NACE Annual Conference and Corrosion Show, Nashville, Tennessee, April 27-May 1, 1992, submitted to Corrosion (1992).

10. A. Goossens and D. D. Macdonald, "Photoelectrochemical Impedance of SteadyState Passivating Films. I. Experimental Technique and First Results of Tungsten," submitted to J. Electroanal. Chem., (1992). 
11. P. C. Searson and D. D. Macdonald, "Frequency Domain Analysis of Photoprocesses at Illuminated Semiconductor Electrodes by Transient Transformation," submitted to J. Electrochem. Soc. (1992).

\section{Lectures}

1. D. D. Macdonald, Invited to present "Probing (and Understanding?) the Passive State" as the Carl Wagner Award Recipient for outstanding work in electrochemistry and corrosion science, Phoenix, AZ, October 13-18, 1991.

2. D. D. Macdonald and M. Urquidi-Macdonald, "The Corrosion Damage Function -Interface Between Corrosion Science and Engineering," presented at CORROSION/92, NACE, Nashville, TN, April 27, 1992.

3. D. D. Macdonald, "Fundamental Issues in the Growth and Breakdown of Passive Films," presented at ALCOA, Pittsburgh, PA, Jan. 23, 1992.

4. D. D. Macdonald and M. Urquidi-Macdonald, "An Advanced Coupled Environment Fracture Model for Predicting Crack Growth Rates," presented to the Parkins Symposium, TMS/ASM Fall Meeting, Oct. 21, 1991.

5. D. D. Macdonald, S. R. Biaggio, and H. Song, "Point Defect Model for Passive Films - Identificatino of Charge Carriers," presented at the Fall Meeting, Electrochem. Soc., Phoeniz, AZ, Oct. 13-18, 1991.

6. D. D. Macdonald, "Electrochemical Modeling of the Cores of Light Water Reactors," presented at the Fall Meeting, Electrochem. Soc., Phoeniz, AZ, Oct. 13-18, 1991.

7. D. D. Macdonald and M. Urquidi-Macdonald, "An Advanced Coupled Environment Fracture Model for Predicting Crack Growth Rates in L.WR Heat Transport Circuits," presented at the Fall Meeting, Electrochem. Soc., Phoeniz, AZ, Oct. 13-18, 1991.

8. D. D. Macdonald and M. Urquidi-Macdonald, "Deterministic Prediction of Localized Corrosion Damage Functions," presented at the Condensing Heat Exchanger Corrosion Meeting, Gas Research Institute, Chicago, IL, February 18, 1992. 
9. D. D. Macdonald, "Calculation of Corrosion Potentials in High Temperature Aqueous Environments," EPRI Workshop on ECP Monitoring and Detection,

... Arlington, VA, Sept. 5-6, 1991.

10. D. D. Macdonald and M. Urquidi-Macdonald, "An Advanced Coupled Environment Fracture Model for Predicting Crack Growth Rates in LWR Heat Transport Circuits," presented at the Fifth Int. Symp. Environ. Degrad. Mat. Nucl. Power Systs. - Water Reactors, ANS/MMMS/NACE, Monterey, CA, August 25-29, 1991.

11. D. D. Macdonald, "Calculation of Redox and Corrosion Potentials in the Cores of Light Water Reactors," presented at the Fifth Int. Symp. Environ. Degrad. Mat. Nucl. Power Systs. - Water Reactors, ANS/MMMS/NACE, Monterey, CA, August 25-29, 1991.

12. D. D. Macdonald, "The Passive State," presented at The Johns Hopkins University, Blatimore, MD, March 4, 1992. 

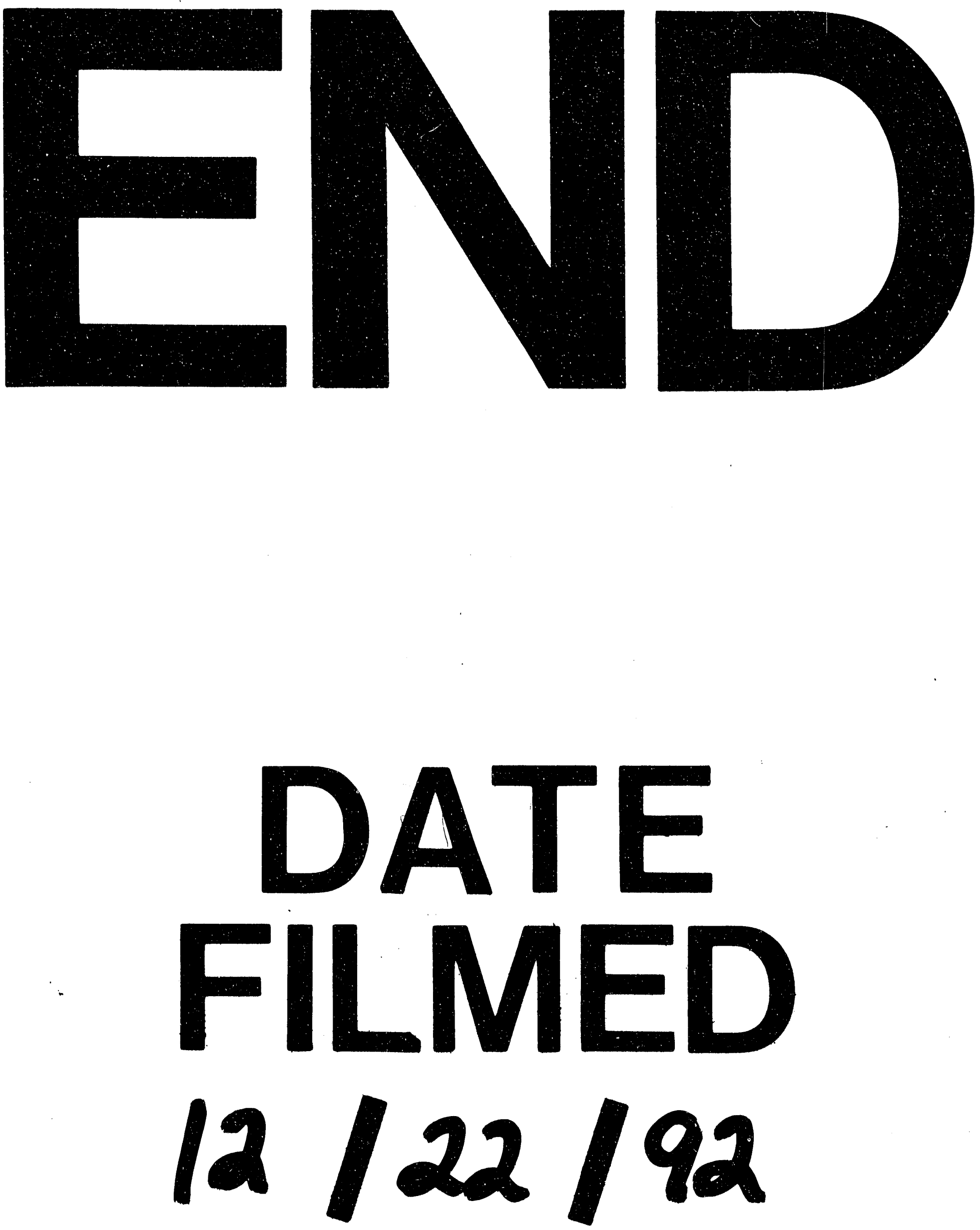

1 
